\title{
A Patient with a Dysembryoplastic Neuroepithelial Tumor Who Underwent Epilepsy Surgery after Initial Seizure
}

\author{
Akiko Kanata $^{a}$ Takato Morioka $^{b}$ Haruhisa Tsukamoto ${ }^{a}$ Toshiro Katsuta $^{a}$ \\ Satoshi O. Suzuki ${ }^{\mathrm{C}}$ \\ ${ }^{a}$ Department of Neurosurgery, Kitakyushu Municipal Medical Center, and ${ }^{b}$ Department of Neurosurgery, \\ Kyushu Rosai Hospital, Kitakyushu, and ' Department of Neuropathology, Graduate School of Medical Sciences, \\ Kyushu University, Fukuoka, Japan
}

\section{Key Words}

Dysembryoplastic neuroepithelial tumor $\cdot$ Cortical dysplasia · Epilepsy surgery · Electrocorticography · Initial seizure

\begin{abstract}
Background: Since dysembryoplastic neuroepithelial tumors (DNTs) are benign tumors that are frequently associated with long-standing medically intractable epilepsy, it is well known that the surgical strategy is resection of the associated epileptogenic zone as well as the tumor. However, the surgical strategy for DNT with a single seizure has not been fully discussed. Methods: We report an 8-year-old boy with DNT in the nondominant frontal lobe who underwent epilepsy surgery at 3 months after his initial seizure. Results: An intraoperative electrocorticogram revealed frequent paroxysmal cortical activity lateral to the tumor. Since resection of the tumor resulted in persistent paroxysmal activity in this cortex, additional resection was performed. The histological findings in the cortex revealed the presence of cortical dysplasia (CD) (Palmini type IIA). Lesionectomy alone might have left the epileptogenic CD. Conclusion: It is thought that
\end{abstract}

epilepsy surgery should be recommended in patients with typical neuroimaging findings of DNT, even if the patients had only one episode of seizure.

Copyright $\odot 2012$ S. Karger AG, Basel

\section{Introduction}

Dysembryoplastic neuroepithelial tumors (DNTs) are glioneuronal tumors that are frequently associated with 'long-standing' medically intractable focal epilepsy in children and young adults, and were initially described by Daumas-Duport et al. [1]. Since DNTs are benign tumors, the aim of surgery is to treat the associated intractable epilepsy, and it is well known that the surgical strategy is resection of the associated epileptogenic zone and the tumor, which are identified by chronic and/or intraoperative electrocorticography (ECoG) [1-16]. However, the surgical strategy in DNT with a single seizure or wellcontrolled seizures has not been fully discussed. We report a patient with DNT who underwent epilepsy surgery at 3 months after the initial seizure.

\section{KARGER}

Fax +4161306 1234 E-Mail karger@karger.ch www.karger.com

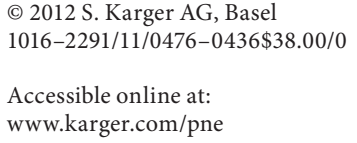



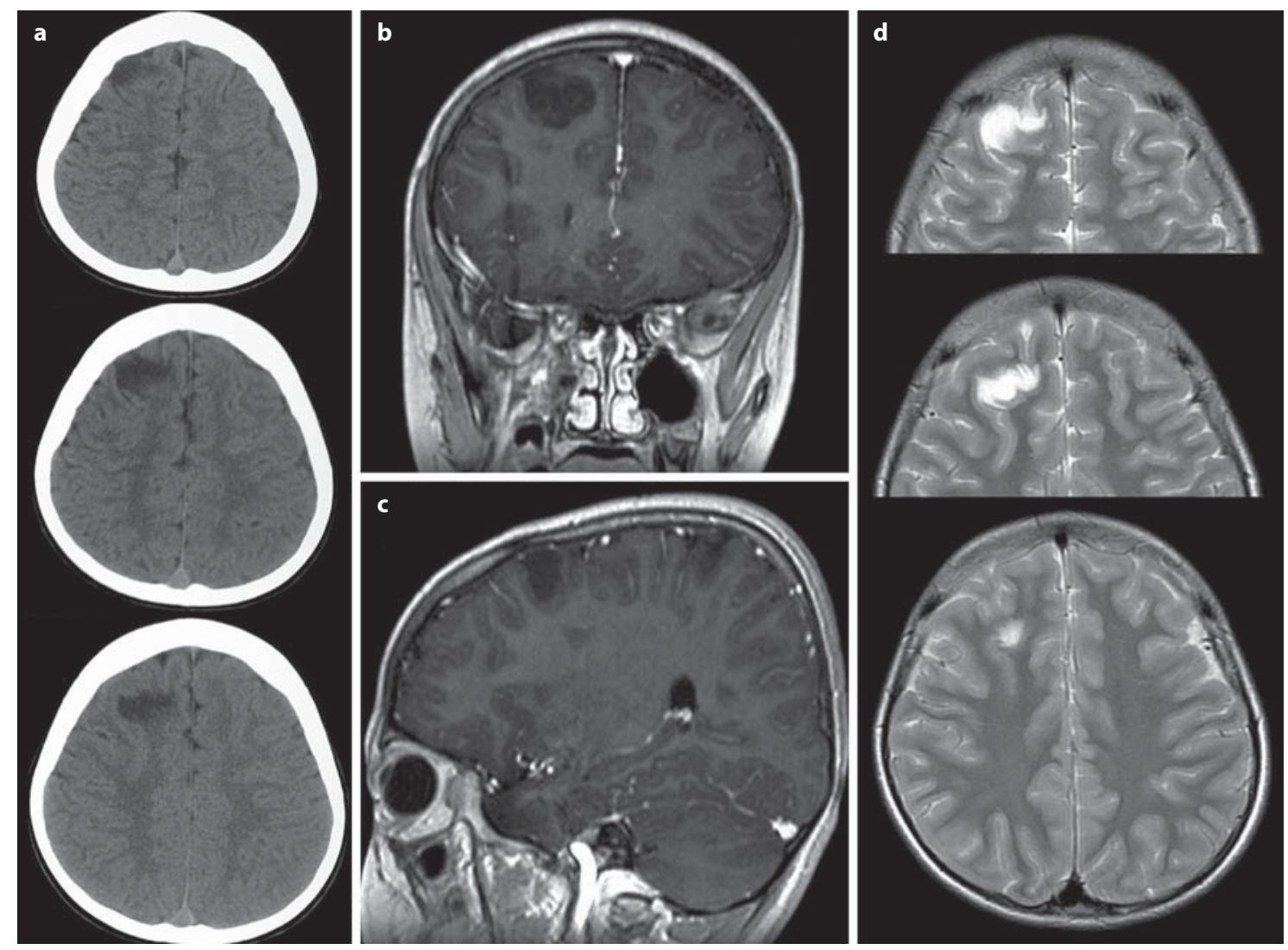

Fig. 1. a Serial axial images of a CT scan demonstrating a low-density tumor in the right frontal lobe. Deformity of the skull overlying the tumor is noted. b, c Coronal (b) and sagittal (c) views of $\mathrm{T}_{1}$-weighted images following gadolinium administration depict a low-intensity tumor in the cortex of the right frontal lobe. A pseudocystic appearance is observed. No gadolinium enhancement is noted. d Serial axial views of $\mathrm{T}_{2}$-weighted images demonstrate a high-intensity tumor in the right frontal lobe.

\section{Case Report}

An 8-year-old right-handed boy suddenly squatted while dancing as part of his school work and subsequently developed a generalized tonic seizure. He was transferred to the pediatric department of the local hospital. An electroencephalogram (EEG) demonstrated frequent paroxysmal discharges in the right frontal region which were treated with $400 \mathrm{mg}$ of valproate. Since a computed tomography (CT) scan revealed a tumor in the right frontal lobe, he was referred to us for tumor resection.

Upon admission, the neurological findings were normal. Although his seizure was completely controlled by valproate monotherapy, the EEGs still revealed frequent paroxysmal activity in the right frontal region (F4 of the 10-20 International System). A CT scan demonstrated a low-density tumor in the right frontal lobe (fig. 1a). Deformity of the skull overlying the tumor was noted. Magnetic resonance imaging (MRI) demonstrated a $\mathrm{T}_{1^{-}}$and $\mathrm{T}_{2}$-prolonged tumor in the cortex of the right frontal lobe (fig. $1 \mathrm{~b}-$ d). A pseudocystic appearance of the tumor was observed (fig. 1b). No gadolinium enhancement was noted (fig. 1b, c).
At 3 months after the initial seizure, a right frontal craniotomy was performed to confirm the histological diagnosis of the tumor. In addition to tumor surgery, epilepsy surgery monitored by intraoperative ECoG was indicated since reduction or cessation of postoperative antiepileptic drug treatment was desired by his parents. Although the tumor was not exposed on the cortex, its location was identified by surface anatomy MR scanning (fig. 2a, b) [17, 18]. The gyrus above the tumor was enlarged. An intraoperative ECoG was recorded from the cortex on and around the tumor, and demonstrated frequent paroxysmal activity, especially over the cortex, just lateral to the tumor (ECoG irritative zone) (fig. 2c). There was a sulcus between the tumor and the ECoG irritative zone (fig. 2b). Resection of the gyrus involving the tumor was performed. Since the ECoG recorded from the cortex around the tumor cavity showed that there was still frequent paroxysmal activity on the ECoG irritative zone lateral to the tumor location, additional resection of this cortex was performed (fig. 2d). The final ECoG demonstrated disappearance of the paroxysmal activity in the right frontal lobe (fig. 2e). 
Fig. 2. a The right anterior quadrant of a surface anatomy MR image clearly demonstrates the anatomical relationship between the low-intensity tumor and the surrounding gyri, sulci and cortical veins. The numbers of the recording electrodes are indicated on this image to show the spatial relationship between the tumor and the recording electrodes. b An intraoperative photograph, the orientation of which is matched with a, demonstrates that the gyrus above the tumor $(\mathrm{T})$ is enlarged, although the tumor is not exposed on the cortex. The white arrows indicate the sulcus between the tumor location and the irritative zone on the intraoperative ECoG (asterisks). c Intraoperative ECoG depicting frequent paroxysmal discharges not on the tumor but on the gyrus just lateral to the tumor (electrode No. 13 and 14). d Intraoperative photograph taken after removal of the tumor showing the special relationship between the surgical defect (white arrows) and the ECoG irritative zone (asterisks). e The final ECoG demonstrates disappearance of the paroxysmal discharges in the right frontal lobe.
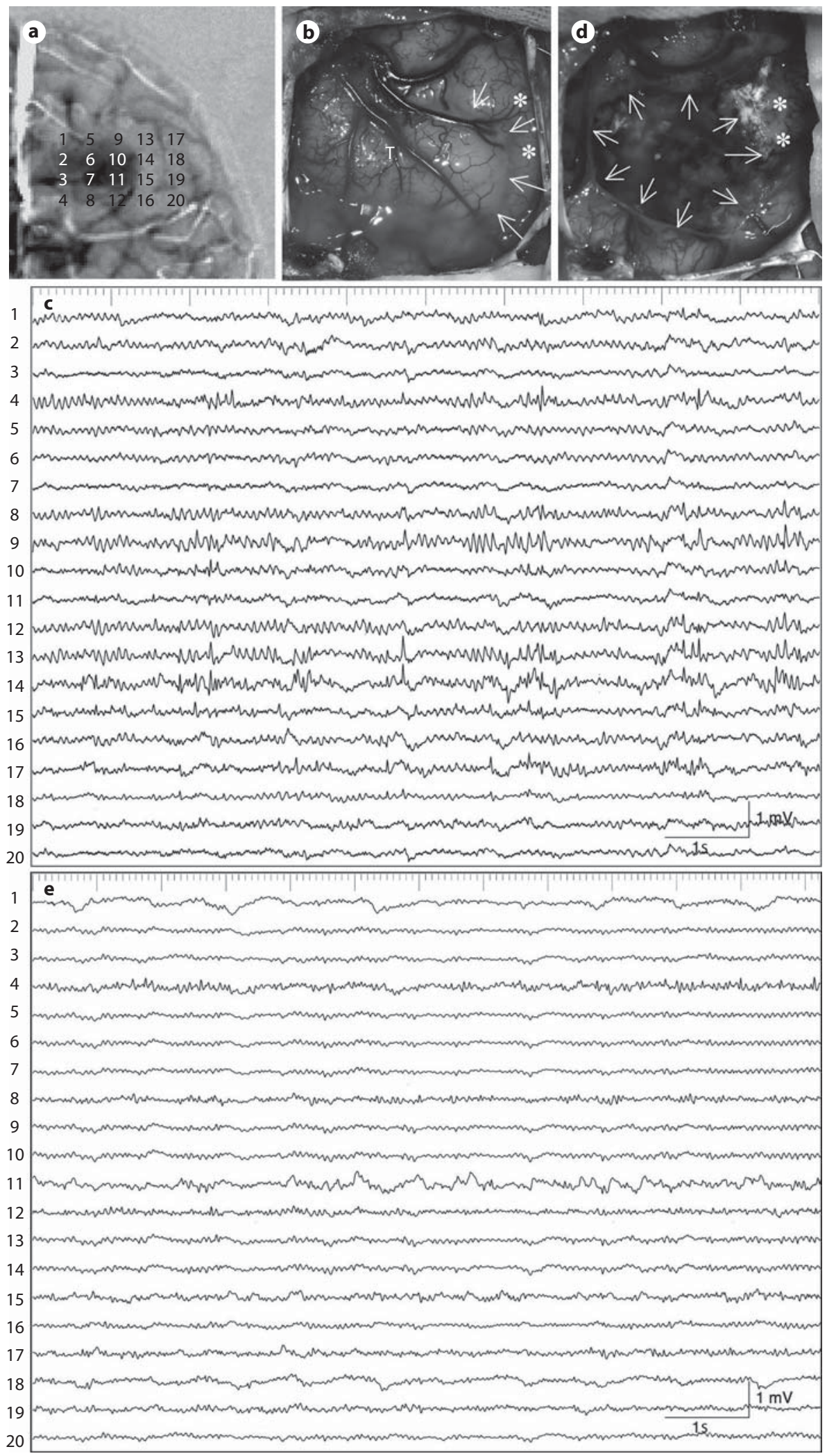

Kanata/Morioka/Tsukamoto/Katsuta/ Suzuki 

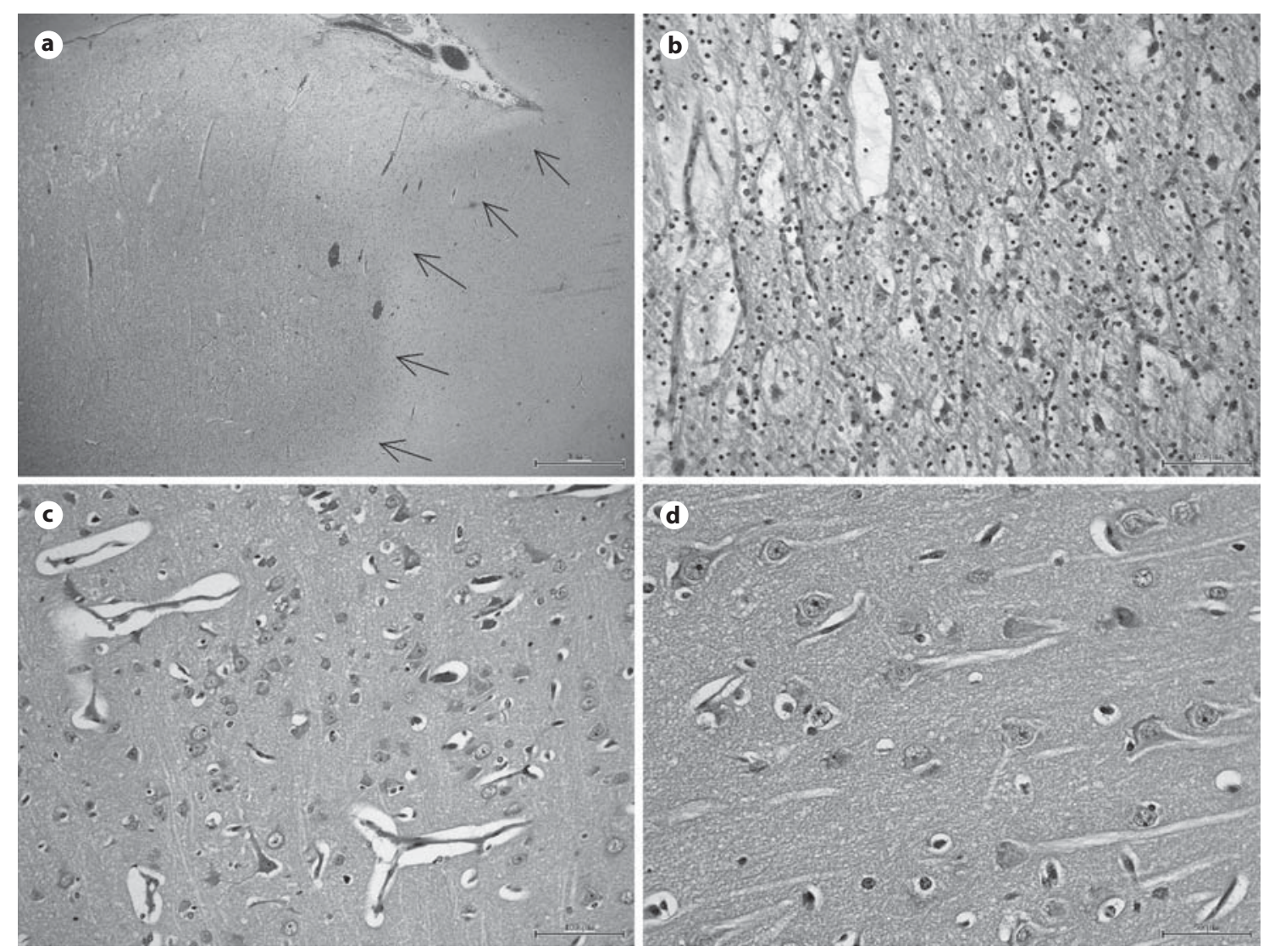

Fig. 3. a The histological findings of the tumor demonstrate a multinodular architecture leading to expansion of the cortex. The arrows indicate the boundary between the tumor and the cortex. HE. Original magnification $\times 2$. b The tumor displays specific glioneuronal elements consisting of ganglion cells suspended within a basophilic mucoid matrix embraced by oligodendroglia-like cells. HE. Original magnification $\times 10$. c As visualized by the intraoperative ECoG, the additionally resected area exhibits dyslamination of the neurons. HE. Original magnification $\times 20$. d Dysmorphic neurons showing clumped Nissl bodies. No balloon cells are present. HE. Original magnification $\times 40$.

The postoperative course was uneventful. With a tapering dose of valproate, the boy was seizure free during the initial 2 years postoperatively. A postoperative EEG showed disappearance of the paroxysmal activity in the right frontal region.

The histopathological findings (hematoxylin and eosin, HE, staining) of the tumor were consistent with those of DNT. The tumor exhibited a multinodular architecture leading to expansion of the cortex. The nodular focus of the tumor was well delineated from the cortex (fig. 3a). The tumor displayed specific glioneuronal elements, such as oligodendroglia-like cells and floating neurons in a myxoid matrix (fig. 3b). The additionally resected ECoG irritative zone exhibited dyslamination of the neurons (fig. 3c) and dysmorphic neurons with clumped Nissl bodies (fig. 3d). Since no balloon cells were present, the findings indicated cortical dysplasia (CD) of Palmini type IIA [19].

\section{Discussion}

Histopathologically, DNT is a benign, predominantly intracortical lesion mainly composed of a population of oligodendrocyte-like cells with admixtures of mature ganglion cells and astrocytes that are located in a myxoid or dense neurofibrillary matrix $[1,5]$. Involvement of the cortical gray matter and a multinodular growth pattern are typical findings $[1,5,20,21]$. On the basis of its histopathological appearance and benign clinical course, it has been demonstrated that the typical radiological features of DNT include a cortical hypodense lesion with deformity of the calvaria adjacent to a superficially located tumor on $\mathrm{CT}$ scans and a $\mathrm{T}_{1}$ - and $\mathrm{T}_{2}$-prolonged tumor with a multicystic appearance on MRI [1, 5, 13, 20-23]. The le- 
sions characteristically lack surrounding edema and only a few are enhanced after addition of contrast material [ 1 , $5,20,21,23]$. The neuroimaging findings in the present case were consistent with those of DNT. However, these reported neuroimaging features are nonspecific and may be seen in a variety of low-grade tumors, particularly gangliogliomas, gangliocytomas, and low-grade astrocytomas [13]. Although functional neuroimages, such as fluorodeoxyglucose and methionine positron emission tomographies (PET) and proton magnetic resonance spectroscopy, especially high methionine uptake on PET, could contribute to do a differential diagnosis from lowgrade astrocytomas, these findings are not conclusive [22, $24]$. Thus, in the present case, tumor surgery was indicated to confirm the histological diagnosis of the tumor.

There is no consensus thus far regarding the timing of the surgery. In a series described by Ostertun et al. [21], one of 16 epileptic patients with DNT underwent surgery at 0.2 years after the onset of epilepsy. Fernandez et al. [20] reported 14 DNT patients, and described that the preoperative duration of epilepsy in 7 patients was 4-9 months. In a recent report by Minkin et al. [10], 12 of 24 DNT patients did not have pharmacoresistant epilepsy. Furthermore, the preoperative minimal duration of epilepsy was reported to be 0.25 years. Thus, it seems that surgical resection of DNT is indicated, regardless of whether or not the patient has 'long-standing' intractable seizures.

With regard to the surgical strategy for control of the 'long-standing' intractable epilepsy associated with DNT, a few authors previously demonstrated that lesionectomy alone of a DNT lesion achieved good outcomes for seizure control $[6,10]$. However, recent studies clearly showed that DNT epileptogenicity is not intrinsic but instead is located in a histologically dysplastic area of the cortex, since DNT is frequently associated with $\mathrm{CD}[1,5,14,16,22-27]$, which has intrinsic epileptogenicity [2, 17]. Recently, Lee et al. [8] demonstrated that amplification of ionotropic glutamate receptors such as GluR2 and GluR3 in the associated CD lesion might be the underlying cause of epileptic seizures. Therefore, it seems necessary to resect the DNT with the associated $\mathrm{CD}$ for effective seizure control $[3,7,9,14,16]$.
15, 22-27], there are surprisingly few reports regarding the topographical relationship between the epileptogenic cortex and the CD location [8, 9, 16]. Mikuni et al. [28] clearly demonstrated a relationship between the ECoG irritative zone and the type Ib (not type II) CD location in a patient with DNT.

In epilepsy surgery, invasive video-intracranial EEG monitoring with subdural grid electrodes is still a gold standard to aid in the localization of the epileptogenic zone and the functionally eloquent zone $[17,18]$. However, in the present case, the tumor location was the nondominant frontal lobe, and placement of a chronic intracranial electrode was too invasive for an 8-year-old boy with only one episode of epilepsy. Thus, epilepsy surgery under the guidance of an intraoperative ECoG was selected according to many previous reports $[4,8,9,11,15$, $22,23,28]$. Although there is no consensus regarding the indication for epilepsy surgery in patients with only one episode of seizure, epilepsy surgery with an intraoperative ECoG could be performed in the present case without additional invasiveness during the tumor surgery.

In our case, the intraoperative ECoG clearly depicted the epileptogenic cortex lateral to the tumor and the histological examination showed a CD lesion in the ECoG irritative zone. There was a sulcus between the tumor and the epileptogenic CD lesion and no continuity was noted between the tumor and the CD lesion. Lesionectomy of the tumor (tumor surgery) alone left behind an epileptogenic $\mathrm{CD}$ in another cortex, which might serve as a focus of recurrent or continued epilepsy $[4,8,9,15,22,23,27$, 28]. Although a long-term follow-up should be performed in the present case, he was seizure free during the first 12 months postoperatively with a tapering dose of antiepileptic drug, and antiepileptic drug cessation is hoped for in the near future. Although a firm conclusion cannot be drawn from a single case report, epilepsy surgery is recommended in patients with typical neuroimaging findings of DNT, even if they have only one episode of seizure.
However, associated small CD lesions are still quite difficult to detect by preoperative neuroimaging examinations, even though the currently available high-resolution MRI techniques have improved the detection of CD compared with past decades $[2,9]$. Therefore, a physiological method that can localize an epileptogenic CD lesion is considered to be important $[4,9,15,22,23]$. Although many previous authors reported that the $\mathrm{CD}$ in DNT patients is focally adjacent to the tumor $[1,4-6,14$,

References
1 Daumas-Duport C, Scheithauer BW, Chodkiewicz J-P, Laws ER Jr, Vedrenne C: Dysembryoplastic neuroepithelial tumor: a surgically curable tumor of young patients with intractable partial seizures. Report of thirtynine cases. Neurosurgery 1988;23:545-556.

2 Aubert S, Wendling F, Regis J, McGonigal A, Figarella-Branger D, Peragut J-C, Girard N, Chauvel P, Bartolomei F: Local and remote epileptogenicity in focal cortical dysplasias and neurodevelopmental tumours. Brain 2010;132:3027-3086.
Kanata/Morioka/Tsukamoto/Katsuta/ Suzuki 
$>$ Bilginer B, Yalnizoglu D, Soylemezoglu F, Turanh G, Cila A, Topcu M, Akalan N: Surgery for epilepsy in children with dysembryoplastic neuroepithelial tumor: clinical spectrum, seizure outcome, neuroradiology, and pathology. Childs Nerv Syst 2009;25: 485-491.

4 Chang EF, Christie C, Sullivan JE, Garcia PA, Tihan T, Gupta N, Berger MS, Barbaro NM: Seizure control outcomes after resection of dysembryoplastic neuroepithelial tumor in 50 patients. J Neurosurg Pediatr 2010; 5:123-130.

5 Daumas-Duport C, Varlet P, Bacha S, Beuvon F, Cervera-Pierot P, Chodkiewicz J-P: Dysembryoplastic neuroepithelial tumors: nonspecific histological forms. A study of 40 cases. J Neurooncol 1999;41:267-280.

6 Giulioni M, Galassi E, Zucchelli M, Volpi L: Seizure outcome of lesionectomy in glioneuronal tumors associated with epilepsy in children. J Neurosurg 2005; 102:288-293.

$>7$ Kameyama S, Fukuda M, Tomikawa M, Morota N, Oishi M, Wachi M, Kanazawa O, Sasagawa M, Kakita A, Takahashi H: Surgical strategy and outcomes for epileptic patients with focal cortical dysplasia or dysembryoplastic neuroepithelial tumor. Epilepsia 2001;42(suppl 6):37-41.

$\checkmark 8$ Lee J, Lee BL, Joo EY, Seo DW, Hong SB, Hong S-C, Suh Y-L, Lee M: Dysembryoplastic neuroepithelial tumors in pediatric patients. Brain Dev 2009;31:671-681.

$\checkmark 9$ Lee M-C, Kang J-Y, Seol M-B, Kim H-S, Woo J-Y, Lee J-S, Jung SJ, Kim J-H, Woo Y-J, Kim M-K, Kim H-I, Kim S-U: Clinical features and epileptogenesis of dysembryoplastic neuroepithelial tumor. Childs Nerv Syst 2006;22:1611-1618.

10 Minkin K, Klein O, Mancini J, Lena G: Surgical strategies and seizure control in pediatric patients with dysembryoplastic neuroepithelial tumors: a single-institution experience. J Neurosurg Pediatr 2008;1:206-210.

-11 Morioka T, Hashiguchi K, Nagata S, Miyagi Y, Yoshida F, Shono T, Mihara F, Koga H, Sasaki T: Additional hippocampectomy in the surgical management of intractable temporal lobe epilepsy associated with glioneuronal tumor. Neurol Res 2007;29:807-815.
12 Nishida N, Hayase Y, Mikuni N, Enatsu R, Hayashi N, Takahashi JA, Nakashima Y, Ikeda A, Amano S, Hashimoto N: A non-specific form of dysembryoplastic neuroepithelial tumor presenting with intractable epilepsy. Brain Tumor Pathol 2005;22:35-40.

13 Raymond AA, Halpin SFS, Alsanjari N, Cook MJ, Kitchen ND, Fish DR, Stevens JM, Harding BN, Scaravilli F, Kendall B, Shorvon SD, Neville BGR: Dysembryoplastic neuroepithelial tumour features in 16 patients. Brain 1994;117:461-475.

- 14 Sakuta R, Otsubo H, Nolan MA, Weiss SK, Hawkins C, Rutka JT, Chuang NA, Chuang SH, Snead OC 3rd: Recurrent intractable seizures in children with cortical dysplasia adjacent to dysembryoplastic neuroepithelial tumor. J Child Neurol 2005;20:377-384.

15 Sandberg DI, Ragheb J, Dunnoyer C, Bhati S, Olavarria G, Morrison G: Surgical outcomes and seizure control rates after resection of dysembryoplastic neuroepithelial tumors. Neurosurg Focus 2005;18(6A):E5.

16 Takahashi A, Hong S-C, Seo DW, Hong SB, Lee M, Suh Y-L: Frequent association of cortical dysplasia in dysembryoplastic neuroepithelial tumor treated by epilepsy surgery. Surg Neurol 2005;64:419-427.

-17 Morioka T, Nishio S, Ishibashi H, Muraishi M, Hisada K, Shigeto H, Yamamoto T, Fukui $\mathrm{M}$ : Intrinsic epileptogenicity of focal cortical dysplasia as revealed by magnetoencephalography and electrocorticography. Epilepsy Res 1999;33:177-187.

18 Morioka T, Shigeto H, Ishibashi H, Nishio S, Yamamoto T, Yoshiura T, Fukui M: Magnetic source imaging of the sensory cortex on the surface anatomy MR scanning (SAS). Neurol Res 1998;20:235-241.

19 Palmini A, Najam I, Avanzini G, Babb T, Guerrini R, Fldvary-Schaefer N, Jackson G, Lueders HO, Prayson R, Spreafico R, Vinters $\mathrm{HV}$ : Terminology and classification of the cortical dysplasia. Neurology 2004;62(suppl 3):S2-S8.
20 Fernandez C, Girard N, Paz Paredes A, Bouvier-Labit C, Lena G, Figarella-Branger D: The usefulness of MR imaging in the diagnosis of dysembryoplastic neuroepithelial tumor in children: a study of 14 cases. AJNR Am J Neuroradiol 2003;24:829-834

21 Ostertun B, Wolf HK, Campos MG, Matus C, Solymosi L, Elger CE, Schramm J, Schild $\mathrm{HH}$ : Dysembryoplastic neuroepithelial tumors: MR and CT evaluation. AJNR Am J Neuroradiol 1996;17:419-430.

-22 Lee DY, Chung CK, Hwang YS, Choe G, Chi JG, Kim HJ, Cho B-K: Dysembryoplastic neuroepithelial tumor: radiological findings (including PET, SPECT, and MRS) and surgical strategy. J Neurooncol 2000;47:167-174.

23 Sharma MC, Jain D, Gupta A, Sarkar C, Suri V, Garg A, Gaikwad SB, Chandra PS: Dysembryoplastic neuroepithelial tumor: a clinicopathological study of 32 cases. Neurosurg Rev 2009;32:161-170.

$>24$ Rosenberg DS, Demarquay G, Jouvet A, Le Bars D, Streichenberger N, Sindou M, Kopp MN, Mauguière F, Ryvlin P: $\left[{ }^{11} \mathrm{C}\right]$-Methionine PET: dysembryoplastic neuroepithelial tumor compared with other epileptogenic brain neoplasms. J Neurol Neurosurg Psychiatry 2005;76:1686-1692.

25 Honavar M, Janota I, Polkey CE: Histological heterogenicity of dysembryoplastic neuroepithelial tumour: identification and differential diagnosis in a series of 74 cases. Histopathology 1999;34:342-356.

$>26$ Prayson RA, Estes ML, Morris HH: Coexistence of neoplasia and cortical dysplasia in patients presenting with seizures. Epilepsia 1993;34:609-615.

27 Prayson RA, Fong J, Najm I: Coexistent pathology in chronic epilepsy patients with neoplasms. Modern Pathol 2010;23:10971103.

28 Mikuni N, Ikeda A, Takahashi JA, Nozaki K, Miyamoto S, Taki W, Hashimoto N: A stepby-step resection guided by electrocorticography for nonmalignant brain tumors associated with long-term intractable epilepsy. Epilepsy Behav 2008;8:560-564. 